\title{
Measuring and decomposing profit inefficiency through the Slacks-Based Measure
}

\author{
Juan Aparicio*, Lidia Ortiz, Jesus T. Pastor \\ Center of Operations Research (CIO). Miguel Hernandez University of Elche (UMH), 03202 Elche (Alicante), Spain
}

\section{A R T I C L E I N F O}

\section{Article history:}

Received 3 June 2016

Accepted 22 December 2016

Available online 27 December 2016

\section{Keywords:}

DATA Envelopment Analysis

Profit inefficiency

Slacks-Based Measure

\begin{abstract}
A B S T R A C T
The Slacks-Based Measure was introduced by Tone (2001) in order to estimate technical efficiency in the input-output space by taking into account all sources of technical inefficiency and satisfying, at the same time, many interesting properties. Since then, the Slacks-Based Measure has attracted the interest of numerous researchers and practitioners. The Slacks-Based Measure has been applied to technical efficiency determination, productivity change measurement, the analysis of production process performance consisting of networks, and so on. However, so far, the Slacks-Based Measure has not been directly related to profit inefficiency as a component of the overall economic performance of firms. In this note, we show how a specific normalized measure of profit inefficiency may be decomposed through the Slacks-Based Measure.
\end{abstract}

(c) 2016 Elsevier B.V. All rights reserved.

\section{Introduction}

In the context of Data Envelopment Analysis (DEA), a Decision Making Unit (DMU) is considered to be technically inefficient if it is possible to expand its output bundle without requiring any increase in its inputs and/or to contract its input bundle without requiring a reduction in its outputs. The potential for augmenting the output bundle reflects output-oriented inefficiency, while potential reduction in inputs means input-oriented inefficiency. In most empirical applications, technical efficiency is measured either in input- or in output-orientation. The selection between one or the other depends on the situation being considered. Additionally, when there is no particular reason to select either the input or output orientation, it is desirable to resort to a technical efficiency measure that includes both input-saving and outputexpanding components. The latter are usually known as graph or non-oriented in contrast to the oriented ones.

DEA measures may also be categorized into two groups. The first one yields projection points on the frontier of the technology without considering whether these are dominated in the sense of Pareto or not. In contrast, the second group ensures that the projection points will be non-dominated, following Koopmans' definition of efficiency (Koopmans, 1951) and that all sources of technical inefficiency are incorporated into the measure.

The first measures to be introduced in DEA were the well-known CCR (Charnes, Cooper, \& Rhodes, 1978) and BCC

\footnotetext{
* Corresponding author.

E-mail address: j.aparicio@umh.es (J. Aparicio).
}

(Banker, Charnes, \& Cooper, 1984), both being based upon oriented and radial models. Seeking Pareto-efficiency in the oriented framework, the Russell input and output measures of technical efficiency were defined (Färe, Grosskopf, \& Lovell, 1985). Regarding the non-oriented context, when the aim is to include both inputsaving and output-expanding components in the efficiency measure, DEA endows practitioners with a toolbox full of possibilities. On the one hand, we may find measures that do not follow the Koopmans definition of technical efficiency, such as the hyperbolic measure (Färe et al., 1985), the directional distance functions (DDF) (Chambers, Chung, \& Färe, 1996, 1998) and the Hölder distance functions (Briec, 1998). On the other hand, and in contrast to the first group of approaches, there is a list of measures that generate projection points on the frontier that are always non-dominated. In this sense, we highlight the family of weighted additive models (Lovell \& Pastor, 1995), which includes, among others, the Measure of Inefficiency Proportions (MIP) and the Range-Adjusted Measure (RAM) (see Cooper, Park, \& Pastor, 1999); the Geometric Distance Function (GDF) by Portela and Thanassoulis (2007) and the SlacksBased Measure (SBM) (Tone, 2001) ${ }^{1}$.

In particular, the Slacks-Based Measure has been applied to many different contexts: technical efficiency determination (e.g., Choi, Zhang, \& Zhou, 2012), productivity change measurement (e.g., Tone, 2004), the analysis of production process performance

\footnotetext{
1 The Slacks-Based Measure is mathematically equivalent to the Enhanced Russell Graph by applying a simple change of variables (see Pastor et al., 1999). However between the two approaches, the most cited model in the literature has been the Slacks-Based Measure.
} 
consisting of networks (e.g., Tone \& Tsutsui, 2009), the measurement of input-specific inefficiency and productivity change (e.g., Kapelko, Horta, Camanho, \& Oude Lansink, 2015), among others.

When information on market prices is available in addition to input and output variables for a set of DMUs, the determination and decomposition of overall economic efficiency may be one of the objectives of the problem. It is worth mentioning that all the aforementioned measures have been related in the literature to overall efficiency except the Slacks-Based Measure. In this respect, some theoretical results are very recent, while others can be dated back to the nineteen-fifties. Farrell (1957) showed how cost efficiency can be decomposed into technical efficiency, the value of the radial measure in the context of DEA, and allocative (price) efficiency. Later, Chambers, Chung, and Färe (1998) proved that a normalized profit inefficiency measure may be associated with the DDF. Briec and Lesourd (1999) proved the same for the Hölder distance functions, while the hyperbolic measure was related to the notion of return to the dollar in Färe, Grosskopf, and Zaim (2002). Additionally, Portela and Thanassoulis (2007) showed that the GDF is linked to a measure of profitability. More recently, Cooper, Pastor, Aparicio, and Borras (2011) and Aparicio, Pastor, and Vidal (2016) related profit inefficiency to the weighted additive models, Aparicio, Pastor, and Ray (2013) showed the existing relationship between a modification of the DDF and the concept of lost profit on outlay, Aparicio, Borras, Pastor, and Vidal (2015) proved that cost (revenue) inefficiency may be decomposed by using the Russell input (output) measure and, finally, Färe, Fukuyama, Grosskopf, and Zelenyuk (2015) used the Directional Slacks-Based Measure to decompose overall inefficiency.

In this note, in order to cover a gap in the DEA literature, we show which measure of overall inefficiency is associated with the SBM and how it can be decomposed into technical and allocative inefficiencies.

\section{Results}

First of all, let us introduce some notation and models.

Working in the usual DEA framework, let us consider $n$ DMUs to be evaluated. $\mathrm{DMU}_{j}$ consumes $x_{j}=\left(x_{1 j}, \ldots, x_{m j}\right) \in R_{++}^{m}$ amounts of input for the production of $y_{j}=\left(y_{1 j}, \ldots, y_{s j}\right) \in R_{++}^{s}$ amounts of output. The relative efficiency of each unit in the sample is assessed with reference to the so-called production possibility set, which can be empirically constructed in DEA from the observations by assuming several postulates (see Banker et al., 1984). In particular, under Variable Returns to Scale (VRS), the production possibility set in DEA, $T$, can be characterized as follows:

$$
\begin{aligned}
T= & \left\{(x, y) \in R_{+}^{m} \times R_{+}^{s}: x_{i} \geq \sum_{j=1}^{n} \lambda_{j} x_{i j}, y_{r} \leq \sum_{j=1}^{n} \lambda_{j} y_{r j},\right. \\
& \left.\sum_{j=1}^{n} \lambda_{j}=1, \lambda_{j} \geq 0, \forall i, r, j\right\} .
\end{aligned}
$$

To evaluate the level of technical efficiency of $\mathrm{DMU}_{0}$ with data $\left(x_{0}, y_{0}\right)$, one can solve the following model, corresponding to the Slacks-Based Measure (Tone, 2001).

$$
\begin{array}{lll}
\operatorname{SBM}\left(x_{0}, y_{0}\right)= & \\
\min & \left(1-\frac{1}{m} \sum_{i=1}^{m} \frac{s_{i 0}^{-}}{x_{i 0}}\right) /\left(1+\frac{1}{s} \sum_{r=1}^{s} \frac{s_{r 0}^{+}}{y_{r 0}}\right) & \\
\text { s.t. } & \sum_{j=1}^{n} \lambda_{j 0} x_{i j}=x_{i 0}-s_{i 0}^{-}, & i=1, \ldots, m \\
& \sum_{j=1}^{n} \lambda_{j 0} y_{r j}=y_{r 0}+s_{r 0}^{+}, & r=1, \ldots, s
\end{array}
$$

$$
\begin{aligned}
& \sum_{j=1}^{n} \lambda_{j 0}=1 \\
& \lambda_{0} \geq 0_{n}, s_{0}^{-} \geq 0_{m}, s_{0}^{+} \geq 0_{s}
\end{aligned}
$$

Tone (2001) showed that model (2) measures technical efficiency taking into account all sources of technical inefficiency (input and output slacks) and that $0 \leq \operatorname{SBM}\left(x_{0}, y_{0}\right) \leq 1$, being equal to one if and only if the assessed unit is Pareto-Koopmans efficient. In this way, $1-\operatorname{SBM}\left(x_{0}, y_{0}\right)$ measures technical inefficiency. Additionally, Tone (2001) proved that model (2) can be transformed into a linear program using the Charnes-Cooper transformation in a similar way to the CCR model (Charnes et al., 1978).

Pastor, Lovell, and Aparicio (2012, p. 116) proved that, under VRS, the following result holds.

$$
\begin{aligned}
& 1-\operatorname{SBM}\left(x_{0}, y_{0}\right)= \\
& \min -\sum_{r=1}^{s} p_{r} y_{r 0}+\sum_{i=1}^{m} c_{i} x_{i 0}+\alpha \\
& \text { s.t. } \sum_{r=1}^{s} p_{r} y_{r j}-\sum_{i=1}^{m} c_{i} x_{i j}-\alpha \leq 0 \text {, } \\
& c_{i} \geq \frac{1}{m x_{i 0}} \text {, } \\
& p_{r} \geq \frac{1}{s y_{r 0}}\left(1+\sum_{r=1}^{s} p_{r} y_{r 0}-\sum_{i=1}^{m} c_{i} x_{i 0}-\alpha\right), \quad r=1, \ldots, s \\
& c \geq 0_{m}, p \geq 0_{s}
\end{aligned}
$$

Eq. (3) implies that the technical inefficiency associated with the Slacks-Based Measure can be equivalently computed through a linear program based on shadow prices, $c \geq 0, p \geq 0_{s}$, and shadow profit, $\alpha \in R$.

We now turn to profit inefficiency measurement. We will exploit the structure of model (3) and some results recently published in Cooper et al. (2011) in order to derive a first upper bound for the term $1-\operatorname{SBM}\left(x_{0}, y_{0}\right)$. This upper bound will take the form of optimal profit minus actual profit, normalized by some specific deflator.

In the context of measuring technical inefficiency by means of the weighted additive model, one should solve the following Linear Programming program.

$$
\begin{aligned}
& W A\left(x_{0}, y_{0}, w^{-}, w^{+}\right)= \\
& \operatorname{Max} \sum_{i=1}^{m} w_{i}^{-} s_{i 0}^{-}+\sum_{r=1}^{s} w_{r}^{+} s_{r 0}^{+} \\
& \text {s.t. } \\
& \begin{array}{ll}
\sum_{j=1}^{n} \lambda_{j 0} x_{i j}=x_{i 0}-s_{i 0}^{-}, & i=1, \ldots, m \\
\sum_{j=1}^{n} \lambda_{j 0} y_{r j}=y_{r 0}+s_{r 0}^{+}, & r=1, \ldots, s \\
\sum_{j=1}^{n} \lambda_{j 0}=1, & \\
s_{i 0}^{-} \geq 0, & i=1, \ldots, m \\
s_{r 0}^{+} \geq 0, & r=1, \ldots, s \\
\lambda_{j 0} \geq 0, & j=1, \ldots, n
\end{array}
\end{aligned}
$$

where $w^{-}=\left(w_{1}^{-}, \ldots, w_{m}^{-}\right) \in R_{++}^{m}$ and $w^{+}=\left(w_{1}^{+}, \ldots, w_{s}^{+}\right) \in R_{++}^{s}$ are weights representing the relative importance of unit inputs and unit outputs. Different paths can be followed in choosing such weights. The most usual possibility selects them based on data and information. In this way, it is possible to achieve a dimensionless optimal value in (4), in the terminology followed by Lovell and Pastor (1995). This line has been followed, for instance, by the Measure of Inefficiency Proportions (MIP) (Cooper et al., 1999) considering $\left(w^{-}, w^{+}\right)=\left(1 / x_{0}, 1 / y_{0}\right)$, where $1 / x_{0}=\left(1 / x_{10}, \ldots, 1 / x_{m 0}\right)$ and $1 / y_{0}=\left(1 / y_{10}, \ldots, 1 / y_{s 0}\right)$; the Range Adjusted Measure of Inefficiency (RAM) (Cooper et al., 1999) considering $\left(w^{-}, w^{+}\right)=$ 
$\left(1 /(m+s) R^{-}, 1 /(m+s) R^{+}\right)$where $R^{-}=\left(R_{1}^{-}, \ldots, R_{m}^{-}\right)$with $R_{i}^{-}=$ $\max _{1 \leq j \leq n}\left\{x_{i j}\right\}-\min _{1 \leq j \leq n}\left\{x_{i j}\right\}, i=1, \ldots, m$, and $R^{+}=\left(R_{1}^{+}, \ldots, R_{s}^{+}\right)$with $R_{r}^{+}=$ $\max _{1 \leq j \leq n}\left\{y_{r j}\right\}-\min _{1 \leq j \leq n}\left\{y_{r j}\right\}, r=1, \ldots, s$; and the Bounded Adjusted Measure (BAM) of inefficiency (see Pastor, Aparicio, Alcaraz, Vidal, \& Pastor, 2015) considering $w^{-}=1 /\left[(m+s)\left(x_{0}-x^{\min }\right)\right]$, where $x^{\mathrm{min}}=\left(x_{1}^{\min }, \ldots, x_{m}^{\min }\right)$ with $x_{i}^{\min }=\min _{1 \leq j \leq n}\left\{x_{i j}\right\}, i=1, \ldots, m$, and $w^{+}=$ $1 /\left[(m+s)\left(y^{\max }-y_{0}\right)\right]$, where $y^{\max }=\left(y_{1}^{\max }, \ldots, y_{m}^{\max }\right)$ with $y_{r}^{\max }=$ $\max _{1 \leq j \leq n}\left\{y_{r j}\right\}, r=1, \ldots, s$. Definitely, input and output weights are usually dependent on data and are homogeneous of degree zero in prices.

Regarding the relationship between profit inefficiency and the weighted additive models, Cooper et al. (2011) proved that:

$\frac{\Pi(c, p)-\left(\sum_{r=1}^{s} p_{r} y_{r 0}-\sum_{i=1}^{m} c_{i} x_{i 0}\right)}{\min \left\{\frac{c_{1}}{w_{1}^{-}}, \ldots, \frac{c_{m}}{w_{m}^{-}}, \frac{p_{1}}{w_{1}^{+}}, \ldots, \frac{p_{s}}{w_{s}^{+}}\right\}} \geq W A\left(x_{0}, y_{0}, w^{-}, w^{+}\right)$,

where $\Pi(c, p)=\max \left\{\sum_{r=1}^{s} p_{r} y_{r}-\sum_{i=1}^{m} c_{i} x_{i}:(x, y) \in T\right\}$ represents the maximum profit given input and output market prices $c=$ $\left(c_{1}, \ldots, c_{m}\right) \in R_{++}^{m}$ and $p=\left(p_{1}, \ldots, p_{s}\right) \in R_{++}^{s}$. In particular, $\Pi(c, p)$ can be calculated in Data Envelopment Analysis under Variable Returns to Scale through (6) (see Ray, 2007).

$\Pi(c, p)=\max _{j=1, \ldots, n}\left\{\sum_{r=1}^{s} p_{r} y_{r j}-\sum_{i=1}^{m} c_{i} x_{i j}\right\}$.

The left hand side of (5) is interpreted in Cooper et al. (2011), in the framework of the additive models, as a profit inefficiency measure: a normalized deviation between optimal profit and observed profit for $\mathrm{DMU}_{0}$ at market prices. Specifically, the normalization represents the minimum among the ratios of market prices to weights. Thanks to the normalization, the left hand side in (5) satisfies a desirable index number property (Nerlove, 1965): it is homogeneous of degree zero in prices, which makes the measure invariant to the currency units for the input and output prices.

Now we are ready to derive the first upper bound for $1-\operatorname{SBM}\left(x_{0}, y_{0}\right)$.

Proposition 1. The next relationship holds.

$\underbrace{\frac{\Pi(c, p)-\left(\sum_{r=1}^{s} p_{r} y_{r 0}-\sum_{i=1}^{m} c_{i} x_{i 0}\right)}{\min \left\{m c_{1} x_{10}, \ldots, m c_{m} x_{m 0}, s p_{1} y_{10}, \ldots, s p_{s} y_{s 0}\right\}}}_{\text {Upperbound-I(UBI) }} \geq 1-\operatorname{SBM}\left(x_{0}, y_{0}\right)$.

Proof. Let $w_{i}^{-}=1 / m x_{i 0}, i=1, \ldots, m$, and $w_{r}^{+}=1 / s y_{r 0}, r=1, \ldots, s$. Pastor et al. (2012), pp. 114-115) showed that $W A\left(x_{0}, y_{0}, 1 / m x_{0}\right.$, $\left.1 / s y_{0}\right)$ can be equivalently calculated by the following linear program:

$$
\begin{array}{lll}
\min & -\sum_{r=1}^{s} p_{r} y_{r 0}+\sum_{i=1}^{m} c_{i} x_{i 0}+\alpha & \\
\text { s.t. } & \sum_{r=1}^{s} p_{r} y_{r j}-\sum_{i=1}^{m} c_{i} x_{i j}-\alpha \leq 0, & j=1, \ldots, n \\
& c_{i} \geq \frac{1}{m x_{i 0}}, & i=1, \ldots, m \\
& p_{r} \geq \frac{1}{s y_{r 0}}, & r=1, \ldots, s \\
& c \geq 0 m, p \geq 0_{s} &
\end{array}
$$

In this way, any $(c, p, \alpha)$ feasible solution of (8) is also a feasible solution of (3) since $p_{r} \geq \frac{1}{s y_{r 0}} \geq$ $\frac{1}{s y_{r 0}}\left(1+\sum_{r=1}^{s} p_{r} y_{r 0}-\sum_{i=1}^{m} c_{i} x_{i 0}-\alpha\right)$ because the objective function in (3) satisfies $0 \leq-\sum_{r=1}^{s} p_{r} y_{r 0}+\sum_{i=1}^{m} c_{i} x_{i 0}+\alpha \leq 1$. This reasoning implies that $W A\left(x_{0}, y_{0}, 1 / m x_{0}, 1 / s y_{0}\right) \geq 1-S B M\left(x_{0}, y_{0}\right)$. Finally, by (5), we get (7).

UB I is our first upper bound for the technical inefficiency of the Slacks-Based Measure. This is in the sense of profit inefficiency, as mentioned before. However, it is possible, as we will go on to show, to establish a better upper bound, in the sense that it will be closer to $1-\operatorname{SBM}\left(x_{0}, y_{0}\right)$ than UB I.

In order to derive our second upper bound, let us consider $\mathrm{DMU}_{0}$ with input-output vector $\left(x_{0}, y_{0}\right) \in T$ and the projection point $\left(x_{0}^{*}, y_{0}^{*}\right)$ derived from the application of model (2). It is well-known that $\left(x_{0}^{*}, y_{0}^{*}\right)=\left(x_{0}-s_{0}^{-*}, y_{0}+s_{0}^{+*}\right) \in T$, where $\left(s_{0}^{-*}, s_{0}^{+*}\right)$ comes from an optimal solution of (2). Then, by the definition of $\Pi(c, p)$, we have that $\Pi(c, p)-\left(\sum_{r=1}^{s} p_{r} y_{r 0}-\sum_{i=1}^{m} c_{i} x_{i 0}\right) \geq$ $\left(\sum_{r=1}^{s} p_{r} y_{r 0}^{*}-\sum_{i=1}^{m} c_{i} x_{i 0}^{*}\right) \quad-\left(\sum_{r=1}^{s} p_{r} y_{r 0}-\sum_{i=1}^{m} c_{i} x_{i 0}\right)=\sum_{r=1}^{s} p_{r} s_{r 0}^{+*}+$ $\sum_{i=1}^{m} c_{i} s_{i 0}^{-*}=\frac{1}{s} \sum_{r=1}^{s} s p_{r} y_{r 0} \frac{s_{r 0}^{+*}}{y_{r 0}}+\frac{1}{m} \sum_{i=1}^{m} m c_{i} x_{i 0} \frac{s_{00}^{-*}}{x_{i 0}} \geq \delta\left(\frac{1}{s} \sum_{r=1}^{s} \frac{s_{r 0}^{+*}}{y_{r 0}}+\right.$ $\frac{1}{m} \sum_{i=1}^{m} \frac{s_{i 0}^{-*}}{x_{i 0}}$ ), where $\delta=\min \left\{m c_{1} x_{10}, \ldots, m c_{m} x_{m 0}, s p_{1} y_{10}, \ldots, s p_{s} y_{s 0}\right\}$. Now, dividing and multiplying the right hand side by the term $\left(1+\frac{1}{s} \sum_{r=1}^{s} \frac{s_{r 0}^{+*}}{y_{r 0}}\right)$ and, finally, moving $\delta\left(1+\frac{1}{s} \sum_{r=1}^{s} \frac{s_{r 0}^{+*}}{y_{r 0}}\right)$ to the left hand side, we get:

$$
\frac{\Pi(c, p)-\left(\sum_{r=1}^{s} p_{r} y_{r 0}-\sum_{i=1}^{m} c_{i} x_{i 0}\right)}{\delta\left(1+\frac{1}{s} \sum_{r=1}^{s} \frac{s_{r 0}^{+*}}{y_{r 0}}\right)} \geq \frac{\left(\frac{1}{s} \sum_{r=1}^{s} \frac{s_{r 0}^{+*}}{y_{r 0}}+\frac{1}{m} \sum_{i=1}^{m} \frac{s_{i 0}^{-*}}{x_{i 0}}\right)}{\left(1+\frac{1}{s} \sum_{r=1}^{s} \frac{s_{r 0}^{+*}}{y_{r 0}}\right)} .
$$

Thanks to expression (9), we may derive the second upper bound for $1-\operatorname{SBM}\left(x_{0}, y_{0}\right)$.

Proposition 2. Let $\left(\lambda_{0}^{*}, s_{0}^{-*}, s_{0}^{+*}\right)$ be an optimal solution of model (2). The next relationship holds.

$$
\underbrace{\frac{\Pi(c, p)-\left(\sum_{r=1}^{s} p_{r} y_{r 0}-\sum_{i=1}^{m} c_{i} x_{i 0}\right)}{\min \left\{m c_{1} x_{10}, \ldots, m c_{m} x_{m 0}, s p_{1} y_{10}, \ldots, s p_{s} y_{s 0}\right\}\left(1+\frac{1}{s} \sum_{r=1}^{s} \frac{s_{r 0}^{+*}}{y_{r 0}}\right)}}_{\text {Upperbound-II(UBII) }}
$$

Proof. $\quad 1-\operatorname{SBM}\left(x_{0}, y_{0}\right)=1-\left(1-\frac{1}{m} \sum_{i=1}^{m} \frac{s_{00}^{-}}{x_{i 0}}\right) /\left(1+\frac{1}{s} \sum_{r=1}^{s} \frac{s_{r 0}^{+}}{y_{r 0}}\right)=$ $\left(\frac{1}{s} \sum_{r=1}^{s} \frac{s_{r 0}^{+*}}{y_{r 0}}+\frac{1}{m} \sum_{i=1}^{m} \frac{s_{i 0}^{-*}}{x_{i 0}}\right) /\left(1+\frac{1}{s} \sum_{r=1}^{s} \frac{s_{r 0}^{+}}{y_{r 0}}\right)$. And applying (9) we get (10).

It is apparent that UB I is greater than or equal to UB II since the term $\left(1+\frac{1}{s} \sum_{r=1}^{s} \frac{s_{r 0}^{+*}}{y_{r 0}}\right) \geq 1$ by (2.4). Nevertheless, the value of UB II is not independent of the existence of alternative optima for model (2). For this reason, we suggest determining the best upper bound for the technical inefficiency of the Slacks-Based Measure by maximizing $\left(1+\frac{1}{s} \sum_{r=1}^{s} \frac{s_{r 0}^{+*}}{y_{r 0}}\right)$ over the alternative optimal solutions of model (2). This can be computed by solving the following linear program. 


$$
\begin{array}{lll}
v^{*}=\max & 1+\frac{1}{s} \sum_{r=1}^{s} \frac{s_{r 0}^{+}}{y_{r 0}} & \\
\text { s.t. } & \sum_{j=1}^{n} \lambda_{j 0} x_{i j}=x_{i 0}-s_{i 0}^{-}, & \\
& \sum_{j=1}^{n} \lambda_{j 0} y_{r j}=y_{r 0}+s_{r 0}^{+}, & r=1, \ldots, s \\
& \sum_{j=1}^{n} \lambda_{j 0}=1, & \\
& 1-\frac{1}{m} \sum_{i=1}^{m} \frac{s_{i 0}^{-}}{x_{i 0}}=\operatorname{SBM}\left(x_{0}, y_{0}\right) \\
& \cdot\left(1+\frac{1}{s} \sum_{r=1}^{s} \frac{s_{r 0}^{+}}{y_{r 0}}\right), \\
& \lambda_{0} \geq 0_{n}, s_{0}^{-} \geq 0_{m}, s_{0}^{+} \geq 0_{s}
\end{array}
$$

Finally, profit, technical and allocative inefficiency linked to the Slacks-Based Measure can be calculated through the following expression:

$$
\begin{gathered}
\underbrace{\frac{\Pi(c, p)-\left(\sum_{r=1}^{s} p_{r} y_{r 0}-\sum_{i=1}^{m} c_{i} x_{i 0}\right)}{\min \left\{m c_{1} x_{10}, \ldots, m c_{m} x_{m 0}, s p_{1} y_{10}, \ldots, s p_{s} y_{s 0}\right\} v^{*}}}_{\text {ProfitInefficiency(PI) }} \\
=\underbrace{1-\operatorname{SBM}\left(x_{0}, y_{0}\right)}_{\text {Technicallnefficiency(TI) }}+A I,
\end{gathered}
$$

where $A I$ is residually derived as $P I-T I$.

PI can, therefore, be decomposed into technical and allocative components. PI is non-negative with nil profit inefficiency signaled when it takes on the value of zero. Indeed, PI satisfies the condition that it is zero if and only if the unit being assessed achieves maximum profit. In addition, we use a deflator (the denominator in PI) to get a profit inefficiency measure homogeneous of degree zero in prices, satisfying the Nerlove (1965) requirements. This means that the value of the profit inefficiency measure is independent of working in euros or dollars, for example. Moreover, PI is also invariant with respect to changes in the measurement units of the quantities (inputs and outputs). We formally establish these two last statements in Proposition 3.

Proposition 3. (i) PI is homogeneous of degree zero in prices. (ii) PI is independent of the units in which the inputs and outputs are measured.

Proof. (i) First, $\operatorname{SBM}\left(x_{0}, y_{0}\right)$, which appears in (11.4), and $v^{*}$ are homogeneous of degree zero in prices since both values come from models (2) and (11), respectively, which are not pricedependent. Second, $\Pi(c, p)$ is homogeneous of degree +1 in prices (see Färe \& Primont, 1995). In the same way, the terms $\left(\sum_{r=1}^{s} p_{r} y_{r 0}-\sum_{i=1}^{m} c_{i} x_{i 0}\right)$ and $\min \left\{m c_{1} x_{10}, \ldots, m c_{m} x_{m 0}, s p_{1} y_{10}, \ldots\right.$, $\left.s p_{s} y_{s 0}\right\}$ are also homogeneous of degree +1 in prices. Consequently, $\frac{\Pi(c, p)-\left(\sum_{r=1}^{s} p_{r} y_{r 0}-\sum_{i=1}^{m} c_{i} x_{i 0}\right)}{\min \left\{m c_{1} x_{10}, \ldots, m c_{m} x_{m 0}, s p_{1} y_{10}, \ldots, s p_{s} y_{s 0}\right\} v^{*}}$ is homogeneous of degree zero in prices. (ii) In order to prove that PI is independent of the units in which the inputs and outputs are measured, note that a change in the measurement units of quantities also affects the value of the original market input and output prices and their corresponding measurement units. For instance, let us suppose that originally input 1 (labor), denoted as $x_{1}$, is measured in hours and its associated market price, denoted as $c_{1}$, is measured in euros per hour. If we change input 1 to be measured in minutes, then $x_{1}^{\text {new }}=$ $60 \cdot x_{1}$ and, necessarily, the change also implies a transformation in the measurement units of the corresponding market price: $c_{1}^{\text {new }}=$ $c_{1} / 60$ [For example, if the firm consumed one hour of labor at 120 euros per hour, then, after the data transformation, it consumes 60 $(=60 \bullet 1)$ minutes at $2(=120 / 60)$ euros per minute]. In this way, let us suppose that the original data is transformed through $x_{i j}^{\text {new }}=k_{i}$. $x_{i j}, k_{i}>0, i=1, \ldots, m, j=1, \ldots, n$, and $y_{r j}^{n e w}=t_{r} \cdot y_{r j}, t_{r}>0, r=1, \ldots$, $s, j=1, \ldots, n$. This implies that the term $\left(\sum_{r=1}^{s} p_{r} y_{r 0}-\sum_{i=1}^{m} c_{i} x_{i 0}\right)$ in (12) is units invariant since $\left(\sum_{r=1}^{s} p_{r}^{\text {new }} y_{r 0}^{\text {new }}-\sum_{i=1}^{m} c_{i}^{\text {new }} x_{i 0}^{\text {new }}\right)=$ $\left(\sum_{r=1}^{s} \frac{p_{r}}{t_{r}} t_{r} y_{r 0}-\sum_{i=1}^{m} \frac{c_{i}}{k_{i}} k_{i} x_{i 0}\right)=\left(\sum_{r=1}^{s} p_{r} y_{r 0}-\sum_{i=1}^{m} c_{i} x_{i 0}\right)$. Using the same arguments and (6), we conclude that $\min \left\{m c_{1} x_{10}, \ldots\right.$, $\left.m c_{m} x_{m 0}, s p_{1} y_{10}, \ldots, s p_{s} y_{s 0}\right\}$ and $\Pi(c, p)$ are also units invariant. In this way, we only need to show that model (11) is units invariant. Let $\left(\lambda_{0}^{*}, s_{0}^{-*}, s_{0}^{+*}\right)$ be an optimal solution of (11). Then we want to prove that $\left(\lambda_{0}^{*}, k s_{0}^{-*}, t s_{0}^{+*}\right)$, with $k s_{0}^{-*}=\left(k_{1} s_{10}^{-*}, \ldots, k_{m} s_{m 0}^{-*}\right)$ and $t s_{0}^{+*}=\left(t_{1} s_{10}^{+*}, \ldots, t_{s} s_{s 0}^{+*}\right)$, is also an optimal solution of model $\left(11^{\prime}\right)$, where $\left(11^{\prime}\right)$ is identical to (11) after the data transformation:

$$
\begin{aligned}
& \max 1+\frac{1}{s} \sum_{r=1}^{s} \frac{s_{r 0}^{+}}{y_{r 0}+W_{0}} \\
& \text { s.t. } \quad \sum_{j=1}^{n} \lambda_{j 0} x_{i j}^{\text {new }}=x_{i 0}^{\text {new }}-s_{i 0}^{-}, \quad i=1, \ldots, m\left(11.1^{\prime}\right) \\
& \sum_{j=1}^{n} \lambda_{j 0} y_{i j}^{n e w}=y_{r 0}^{n e w}+s_{r 0}^{+}, \quad r=1, \ldots, s \\
& \sum_{j=1}^{n} \lambda_{j 0}=1 \\
& 1-\frac{1}{m} \sum_{i=1}^{m} \frac{s_{i 0}^{-}}{x_{i 0}^{\text {nio }}}=\operatorname{SBM}\left(x_{i 0}^{\text {new }}, y_{r 0}^{\text {new }}\right) \\
& \cdot\left(1+\frac{1}{s} \sum_{r=1}^{s} \frac{s_{r 0}^{+}}{y_{r 0}^{\text {now }}}\right) \text {, } \\
& \lambda_{0} \geq 0_{n}, s_{0}^{-} \geq 0_{m}, s_{0}^{+} \geq 0_{s}
\end{aligned}
$$

Regarding the constraints of $\left(11^{\prime}\right)$, it is trivial that $\left(\lambda_{0}^{*}, k s_{0}^{-*}, t s_{0}^{+*}\right)$ satisfies $\left(11.3^{\prime}\right)$. As for $\left(11.1^{\prime}\right)$, we have that $\sum_{j=1}^{n} \lambda_{j 0}^{*} x_{i j}^{\text {new }}=x_{i 0}^{\text {new }}-k_{i} s_{i 0}^{-*} \Leftrightarrow \sum_{j=1}^{n} \lambda_{j 0}^{*} k_{i} x_{i j}=k_{i} x_{i 0}-k_{i} s_{i 0}^{-*} \Leftrightarrow \sum_{j=1}^{n}$ $\lambda_{j 0}^{*} x_{i j}=x_{i 0}-s_{i 0}^{-*}$. Therefore, $\left(11.1^{\prime}\right)$ is satisfied for all $i=1, \ldots, m$. The same arguments can be used for $\left(11.2^{\prime}\right)$. As for $\left(11.4^{\prime}\right)$, note that the Slacks-Based Measure is units invariant (see Tone, 2001) and, consequently, $\operatorname{SBM}\left(x_{0}, y_{0}\right)=\operatorname{SBM}\left(x_{0}^{\text {new }}, y_{0}^{\text {new }}\right)$. In this way, we have that

$$
\begin{aligned}
& 1-\frac{1}{m} \sum_{i=1}^{m} \frac{k_{i} s_{i 0}^{-*}}{x_{i 0}^{\text {new }}}=\operatorname{SBM}\left(x_{0}^{\text {new }}, y_{0}^{\text {new }}\right) \cdot\left(1+\frac{1}{s} \sum_{r=1}^{s} \frac{t_{r} s_{r 0}^{+*}}{y_{r 0}^{\text {new }}}\right) \Leftrightarrow \\
& 1-\frac{1}{m} \sum_{i=1}^{m} \frac{k_{i} s_{i 0}^{-*}}{k_{i} x_{i 0}}=\operatorname{SBM}\left(x_{0}, y_{0}\right) \cdot\left(1+\frac{1}{s} \sum_{r=1}^{s} \frac{t_{r} s_{r 0}^{+*}}{t_{r} y_{r 0}}\right) \Leftrightarrow \\
& 1-\frac{1}{m} \sum_{i=1}^{m} \frac{s_{i 0}^{-*}}{x_{i 0}}=\operatorname{SBM}\left(x_{0}, y_{0}\right) \cdot\left(1+\frac{1}{s} \sum_{r=1}^{s} \frac{s_{r 0}^{+*}}{y_{r 0}}\right) .
\end{aligned}
$$

Therefore, $\left(\lambda_{0}^{*}, k s_{0}^{-*}, t s_{0}^{+*}\right)$ is a feasible solution of $\left(11^{\prime}\right)$ and yields an objective value equal to $1+\frac{1}{s} \sum_{r=1}^{s} \frac{t_{r} r_{r 0}^{+*}}{y_{r 0}^{\text {new }}}=1+$ $\frac{1}{s} \sum_{r=1}^{s} \frac{t_{r} s_{r 0}^{+*}}{t_{r} y_{r 0}}=1+\frac{1}{s} \sum_{r=1}^{s} \frac{s_{r 0}^{+*}}{y_{r 0}}=v^{*}$. If there exists $\left(\hat{\lambda}_{0}, \hat{s}_{0}^{-}, \hat{s}_{0}^{+}\right)$feasible solution of $\left(11^{\prime}\right)$ such that $1+\frac{1}{s} \sum_{r=1}^{s} \frac{\hat{s}_{r 0}^{+}}{y_{r 0}^{\text {new }}}>v^{*}$, then it is easy to show that $\left(\hat{\lambda}_{0}, \hat{s}_{0}^{-} / k_{i}, \hat{s}_{0}^{+} / t_{r}\right)$ is a feasible solution of the original (11). But then it produces an objective function value that equals $1+\frac{1}{s} \sum_{r=1}^{s} \frac{\hat{s}_{r 0}^{+} / t_{r}}{y_{r 0}}=1+\frac{1}{s} \sum_{r=1}^{s} \frac{\hat{s}_{r 0}^{+}}{t_{r} y_{r 0}}=1+\frac{1}{s} \sum_{r=1}^{s} \frac{\hat{s}_{r 0}^{+}}{y_{r 0}^{\text {now }}}>v^{*}$, which is not possible. Accordingly, $\left(\lambda_{0}^{*}, k s_{0}^{-*}, t s_{0}^{+*}\right)$ is an optimal solution of $\left(11^{\prime}\right)$ and the optimal value of $\left(11^{\prime}\right)$ coincides with $v^{*}$. In this way, we have that no terms that appear in PI depend on the units in which the variables are measured. Consequently, PI is independent of the units in which the inputs and outputs are measured, as we were seeking to prove.

Finally, it is worth mentioning that all these results derived for the Slacks-Based Measure can be equivalently developed for the 
Enhanced Russell Graph (ERG) (see Pastor, Ruiz, \& Sirvent, 1999), simply by substituting SBM by ERG in (12).

\section{Conclusions}

In this note, we have shown how the well-known Slacks-Based Measure can be related to profit inefficiency. We have also derived a decomposition of overall inefficiency into technical and allocative inefficiencies, thus endowing practitioners interested in using the Slacks-Based Measure, with a tool to measure and decompose profit inefficiency when market prices are available.

Future research efforts should focus on the development of new decompositions of profit inefficiency related to the Slacks-Based Measure. In particular, we are referring to the traditional and nonlinear Russell 'Graph' Measure (see Färe et al., 1985), which continues without decomposition in the literature. Furthermore, the application of the approach developed in this note to real-life datasets is clearly another interesting line of future research. Finally, a comparison of all the existing alternative decompositions of profit inefficiency (those based upon the directional distance functions, the weighted additive models and the Slacks-Based Measure) should be carried out resorting to a battery of simulated databases in order to check the benefits of each approach.

\section{Acknowledgments}

The authors would like to thank two anonymous referees for their helpful comments and suggestions and acknowledge the financial support from the Spanish Ministry of Economy and Competitiveness under grant MTM2013-43903-P.

\section{References}

Aparicio, J., Pastor, J. T., \& Ray, S. C. (2013). An overall measure of technical inefficiency at the firm and at the industry level: The 'lost profit on outlay'. European Journal of Operational Research, 226(1), 154-162.

Aparicio, J., Borras, F., Pastor, J. T., \& Vidal, F. (2015). Measuring and decomposing firm's revenue and cost efficiency: The Russell measures revisited. International Journal of Production Economics, 165, 19-28.

Aparicio, J., Pastor, J. T. \& Vidal, F. (2016). The weighted additive distance function. European Journal of Operational Research, 254, 338-346.

Banker, R. D., Charnes, A., \& Cooper, W. W. (1984). Some models for estimating technical and scale inefficiencies in data envelopment analysis. Management Science, 30, 1078-1092.

Briec, W. (1998). Hölder distance function and measurement of technical efficiency. Journal of Productivity Analysis, 11(2), 111-131.

Briec, W., \& Lesourd, J. B. (1999). Metric distance function and profit: Some duality results. Journal of Optimization Theory and Applications, 101(1), 15-33.
Chambers, R. G., Chung, Y., \& Färe, R. (1996). Benefit and distance functions. Journal of Economic Theory, 70, 407-419.

Chambers, R. G., Chung, Y., \& Färe, R (1998) Profit, directional distance functions, and Nerlovian efficiency. Journal of Optimization Theory and Applications, 98(2), 351-364.

Charnes, A., Cooper, W. W., \& Rhodes, E. (1978). Measuring the efficiency of decision making units. European Journal of Operational Research, 2/6, 429-444.

Choi, Y., Zhang, N., \& Zhou, P. (2012). Efficiency and abatement costs of energy-related $\mathrm{CO}_{2}$ emissions in China: A slacks-based efficiency measure. Applied Energy, 98, 198-208.

Cooper, W. W., Park, K. S., \& Pastor, J. T. (1999). RAM: A range adjusted measure of inefficiency for use with additive models, and relations to other models and measures in DEA. Journal of Productivity Analysis, 11, 5-42.

Cooper, W. W., Pastor, J. T., Aparicio, J., \& Borras, F. (2011). Decomposing profit inefficiency in DEA through the weighted additive model. European Journal of Operational Research, 212(2), 411-416.

Färe, R., Grosskopf, S., \& Lovell, C. A. K. (1985). The measurement of efficiency of production. Kluwer Nijhof Publishing.

Färe, R., \& Primont, D. (1995). Multi-output production and duality: Theory and applications. Kluwer Academic Publishers.

Färe, R., Grosskopf, S., \& Zaim, O. (2002). Hyperbolic efficiency and return to the dollar. European Journal of Operational Research, 136(3), 671-679.

Färe, R., Fukuyama, H., Grosskopf, S., \& Zelenyuk, V. (2015). Decomposing profit efficiency using a slack-based directional distance function. European Journal of Operational Research, 247(1), 335-337.

Farrell, M. J. (1957). The measurement of productive efficiency. Journal of the Royal Statistical Society, Series A, General, 120, 253-281.

Kapelko, M., Horta, I. M., Camanho, A. S., \& Oude Lansink, A. (2015). Measurement of input-specific productivity growth with an application to the construction industry in Spain and Portugal. International Journal of Production Economics, 166 64-71.

Koopmans, T. C. (1951). Analysis of production as an efficient combination of activities. In T. C. Koopmans (Ed.), Activity analysis of production and allocation. New York: John Wiley.

Lovell, C. K., \& Pastor, J. T. (1995). Units invariant and translation invariant DEA models. Operations Research Letters, 18(3), 147-151.

Nerlove, M. (1965). Estimation and identification of Cobb-Douglas production functions. Rand McNally Company.

Pastor, J. T., Ruiz, J. L., \& Sirvent, I. (1999). An enhanced DEA Russell graph efficiency measure. European Journal of Operational Research, 115, 596-607.

Pastor, J. T., Lovell, C. A. K., \& Aparicio, J. (2012). Families of linear efficiency programs based on Debreu's loss function. Journal of Productivity Analysis, 38: 109120.

Pastor, J. T., Aparicio, J., Alcaraz, J., Vidal, F., \& Pastor, D. (2015). An enhanced BAM for unbounded or partially bounded CRS additive models. Omega, 56, 16-24.

Portela, M. C. A. S., \& Thanassoulis, E. (2007). Developing a decomposable measure of profit efficiency using DEA. Journal of the Operational Research Society 58, 481-490.

Ray, S. C. (2007). Shadow profit maximization and a measure of overall inefficiency. Journal of Productivity Analysis, 27, 231-236.

Tone, K. (2001). A slacks-based measure of efficiency in data envelopment analysis European Journal of Operational Research, 130(3), 498-509.

Tone, K. (2004). Malmquist productivity index. Efficiency change over time. In W. W. Cooper, L. M. Seiford, \& J. Zhu (Eds.), Handbook on data envelopment analysis. Boston: Kluwer Academic Publishers.

Tone, K., \& Tsutsui, M. (2009). Network DEA: A slacks-based measure approach. European Journal of Operational Research, 197, 243-252. 